$\xi=$

\title{
Design of Packaging Materials Based on Polylactide and Wood Filler
}

\author{
R.R. Safin, G.A. Talipova, N.R. Galyavetdinov
}

Kazan National Research Technological University, Kazan, Russia

\begin{abstract}
Packaging is one of the primary factors that influence the consumer's decision to purchase a product. Competent packaging design makes it possible to distinguish the product from competitors' products, to attract the attention of the target audience, to raise the mood of the buyer, and to cause trust in the brand. Currently, packaging materials from various types of polymers are a popular and widely used type of packaging, but at the same time such materials pose a serious burden on the environment. In this regard, the development of new types of biodegradable materials for the packaging industry is relevant. The article considers the possibility of using a composite material for packing based on polylactide (PLA) and filler from crushed biomass waste. It was established that PLA packaging with the addition of $50 \%$ wood filler will provide high strength characteristics with the ability to create container packaging, as well as provide a high rate of biodegradation of used packaging, thereby reducing the environmental burden on the environment. At the same time, the cost of such a composite will be comparable to the cost of synthetic polymers obtained from non-renewable hydrocarbon raw materials.
\end{abstract}

Key words: design, packaging material, biodegradable polymer, polylactide, wood filler, thermal modification.

\section{Introduction}

Packaging design is one of the most powerful marketing tools for product promotion. This is a kind of communication channel between the manufacturer and its target audience. The more attractive the product, the more popular it will be. The cunning move can significantly increase the percentage of sales. It is wellknown that a beautiful, bright, bright container helps to ensure that it will be bought both deliberately and spontaneously. Every smallest element must be worked out and thought out. It is important to create it so that it works for the brand, its success.

At the same time, in the conditions of the continuous development of the industry, the packaging industry should pay special attention to the integrity of the relationship between the products produced and the environment. The problem of environmental protection is now becoming global. In particular, the rapid and practically uncontrollable growth in consumption of synthetic plastics in many industries, leading to a sharp increase in waste, is a serious concern. The main part of this waste is various packaging materials.

One of the solutions to the problems of disposal of polymer waste packaging industry is the use of biodegradable materials. Currently, a lot of biodegradable materials are produced that can be used by the packaging industry: based on copolymers of polyhydroxybutyrate and polyhydroxyvalerate - Biopol material (ICI, United Kingdom); hydroxycarboxylic acid and its lactide Novon (Wamer-Lampert \& Co, USA); based on cellulose acetate with various additives and plasticizers - Biocell (France); based on polyamide- $6(6,6)$ with additives of natural origin and synthetic biodegradable oligomers - Mater-Bi (Italy); In the United States, caprolactam-based TONE outdoor packs are widely used in the United States. However, they all share the high cost compared to materials based on hydrocarbons [5]. In this regard, in recent years, interest has increased in polylactide, a polymer from renewable raw materials, the cost of which on the market is on average just two times higher than the cost of polyethylene. At the same time, this cost can be reduced by creating a composite material: mixing polylactide with wood filler, for example, wood flour.

Polylactide is transparent, thermoplastic, it is possible to make dishes for single use, food packaging and films from it (Fig. 1). The processing of this polymer is performed by any means suitable for synthetic polymers [3]. Polymeric materials provide more opportunities to diversify packaging design: such packaging can be transparent or impermeable, painted, with metal or wooden inserts, with sputtering, etc.

The introduction of biodegradable polymer into production opens up new possibilities in packaging design [4]. It will preserve the ecology for future generations, while the PLA will not yield in its decorative possibilities to synthetic non-decomposable polymers. Their properties do not limit the design possibilities and meet the strict environmental standards of the leading countries of the world.

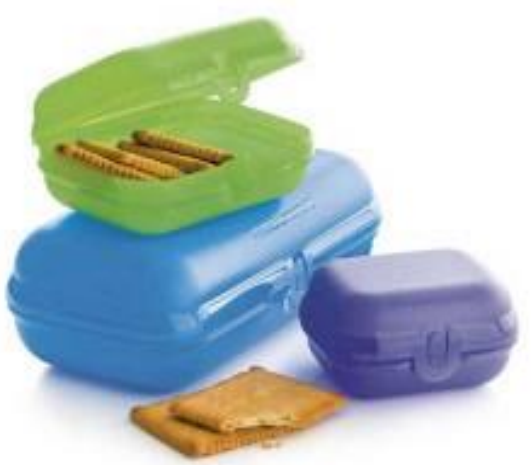

Fig. 1: Food packaging based on polylactide 
At the development stage of polylactide packaging, the selection of PLA (specific brand and other characteristics), the definition of the shape, overall dimensions, color scheme of the future packaging, the development of text and images, design are carried out.

The process of packaging design includes the development of a drawing of a package sweep, the development of a graphic design of a package, the layout of a graphic design of a package and the manufacture of a prototype. The main tool for automating the development of drawing packaging is CAD systems - computeraided design systems.

Since complex tests confirm that the functional properties and suitability for thermoforming of these materials are comparable to those of other polymers obtained on the basis of oil and gas products, it can be noted that the technologies used in the production of packaging materials based on PLA will be similar [6 ]. In addition, PLA has the advantage that the melting point of this material is slightly lower than the recommended melting point of polyethylene or its other analogues. Consequently, this gives a reduction in the cost of production per unit of production [2].

However, it should be noted that the cost of production of polylactide today remains high, which is an inhibiting factor in the development of packaging bioproducts. That is why, to reduce the cost of biopolymers, efforts were made to mix PLA with thermally modified wood flour, acting as a filler in the composite. At the same time, the low melting point of the polymer makes it possible to use fillers in the form of wood waste in the production of packages, since at low temperatures the production of the composite does not result in the destruction of wood fibers in the composite itself. In addition, the addition of thermally modified wood flour allows to obtain composites with a given color palette and the necessary physicomechanical and aesthetic properties depending on the heat treatment temperature of the wood filler itself [1]. This will allow to produce packaging products, clearly distinguished by the saturation of the color solution, and expand the scope of application of these composites on the market. It should be noted that packaging materials must not only have an attractive appearance and fully comply with the requirements of the information function, i.e. reflect the individual characteristics of the product, provide the necessary information about it, but also satisfy a variety of physical and mechanical characteristics, such as strength, dimensional stability, etc.

\section{Research method}

To study the properties of biocomposites, polylactide composite samples were made with various contents, both thermally treated at $\mathrm{t}=200^{\circ} \mathrm{C}$ and untreated wood filler (Table 1).

Initially, blanks for samples were obtained by mixing the components at a temperature of $180^{\circ} \mathrm{C}$. Further, these blanks were placed in a mold at a temperature of $180^{\circ} \mathrm{C}$, after which samples of composites were obtained for further studies of their properties.

Table 1: Composition of composite samples

\begin{tabular}{|c|c|c|c|}
\hline $\begin{array}{c}\text { Sample } \\
\text { No. }\end{array}$ & PLA, \% & Woody filler, \% & $\begin{array}{c}\text { General } \\
\text { content, } \%\end{array}$ \\
\hline 1 & 100 & 0 & 100 \\
\hline 2 & 70 & 30 & 100 \\
\hline 3 & 50 & 50 & 100 \\
\hline 4 & 50 & $\begin{array}{c}50 \\
(\text { heat treated } \\
\left.\text { at } \mathrm{t}=200^{\circ} \mathrm{C}\right)\end{array}$ & 100 \\
\hline
\end{tabular}

In order to study the processes of biodegradation of polylactic acid, studies were conducted in which samples of the obtained composite were placed at a depth of no more than $30 \mathrm{~cm}$. After a certain amount of time, samples were removed and samples were measured and visually inspected.
To determine the physicomechanical properties of the composites, the ZFG-2000 device was used, to determine the tensile strength the tensile testing machine RMG-MG4.

\section{Results and analysis}

Figures 2 and 3 show the strength properties of pure polylactide, as well as untreated and thermally treated wood fillers with different fiber content by weight. It should be noted that the heat treatment of the filler was carried out in a conductive manner at $t$ $=200^{\circ} \mathrm{C}$. From the histograms it can be seen that the tensile strength of the composites gradually decreases with increasing mass content of the filler. Moreover, the tensile strength of composite materials with thermally treated filler was higher than that of composites with unmodified wood flour.

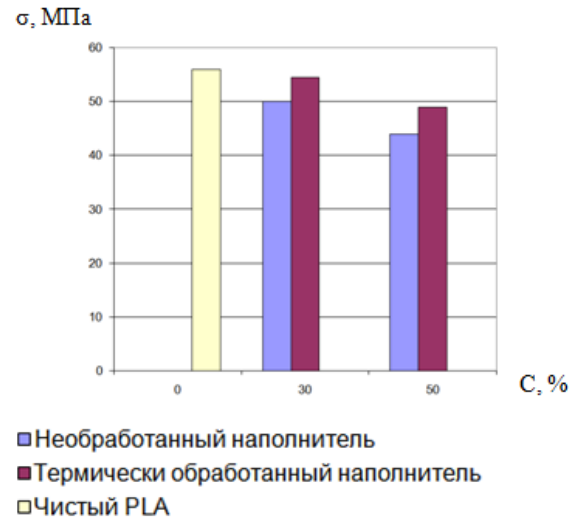

Fig. 2: The tensile strength of the composite on the gap from the content of the filler

With regards to the modulus of elasticity, it can be noted that the tensile strength of wood-filled biodegradable composite materials was higher than fiber PLA (Fig. 3). Also, the results were lower for a composite with a thermally modified filler compared to a composite of raw filler.

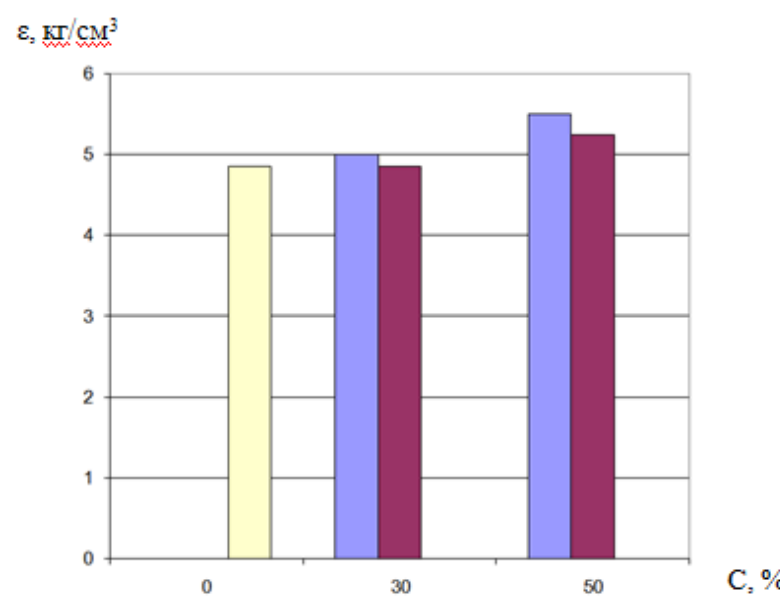

\section{口Необработанный наполнитель \\ вТермически обработанный наполнитель 口Чистый PLA}

Fig. 3: The dependence of the modulus of elasticity on the content of wood filler in the composite

During the research it was revealed that the destruction of the PMK in the compost occurs in a two-step process. In the initial phases of degradation, the chains of high molecular weight PMA are hydrolyzed to oligomers with a lower molecular weight. This reaction can be accelerated by acids or bases, and also depends on temperature and humidity. Fragmentation (crushing) of the 
composite occurs earlier on composite samples, in which the content of wood filler is maximal. Therefore, any factor that increases the susceptibility of the PMK matrix to hydrolysis ultimately controls the destruction of the PMK. Unlike weight loss or fragmentation, which reflect structural changes in the test sample, $\mathrm{CO} 2$ emission is an indicator of the final biodegradation, that is, the mineralization of the test samples [7].

In fig. 4 shows experimental curves showing the approximate time of destruction of polylactide and composites based on it Experimental results clearly show that the biodegradability of the PMK component in the pure polylactide composite without the addition of wood filler is significantly lower. A visual reflection of the PMK behavior in samples of wood-filled composite, showing a slightly higher rate of biodegradation, can also be seen in Fig. four.

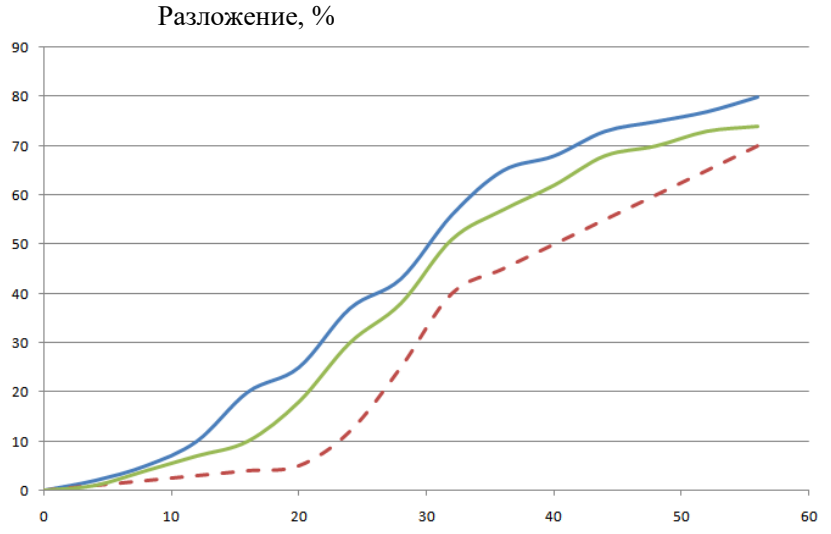

Fig. 4: Destruction of composites depending on the time PLA / wood filler: 1 - 50/50; 2 - 50/50 (term); 3 - clean PLA

It should be noted that the introduction of fillers into the PLA matrix resulted in a slight decrease in the molecular weight of the matrix. It is known that PLA with a relatively low molecular weight may have a higher rate of enzymatic degradation, for example, due to the high concentration of accessible end groups of the chain [8]. However, in these cases, the rate of change in molecular weight of pure PLA and PLA in different composites is almost the same. Thus, the initial molecular weight is not the main factor affecting the ability of composites to degrade [9]. Another factor affecting the ability to degrade PLA in composites is the varying degree of dispersion of the filler layers in the polymer matrix, which actually depends on the quality of the filler itself. Therefore, it is possible to regulate the ability of PLA to degrade using the correct selection of the quantity and quality of wood filler added.

In addition to the physicomechanical characteristics, the properties of the surface of the composite and the effect on the quality of the impression of printing on the surface of the packaging material were studied. Unlike paper, a traditional printed material, the physicomechanical and surface properties of polymer films have a much greater influence on the process and print quality. Especially when it comes to the passage of the film through the tape path of the printing equipment. However, the results of the tests showed a significant improvement in the impression of printing on the surface of composites with a filler compared to pure PLA, which allows to conclude that the use of wood filler in the composition of biodegradable packaging material is relevant.

\section{Conclusion}

According to the analysis of the relationship of sales of goods and packaging design, it can be noted that considering the results of sociological research, approximately $70-75 \%$ of buyers make the final choice about making a purchase of a product directly in front of the showcase.
From this we can conclude that only a quarter of the target audience prefers certain brands, the other consumers are in the "free search". In many ways, the choice of people determines the visual appeal of the product. This means that when combining a bright appearance with a sufficiently high quality of products, there is a high probability that the customer will return to the store more than once for the goods they like.

In this article, a comprehensive analysis was carried out, allowing you to make the optimal choice of the quantitative composition for the manufacture of packaging from a biodegradable polymer polylactide, to reduce the cost of which was created a composition with thermally modified wood filler.

In the course of the work, experimental studies were conducted, the results of which were used to obtain the physicomechanical characteristics of wood-filled composites, indicating the possibility of their use in the production of cheap biodegradable packaging. It was established that PLA packaging with the addition of $50 \%$ wood filler will provide high strength characteristics with the ability to create container packaging, as well as provide a high rate of biodegradation of the used packaging, thereby reducing the environmental burden on the environment. At the same time, the cost of such a composite will be comparable to the cost of synthetic polymers obtained from non-renewable hydrocarbon raw materials.

\section{References}

[1] R. R. Khasanshin, R. R. Safin, E. Y. Razumov, High Temperature Treatment of Birch Plywood in the Sparse Environment for the Creation of a Waterproof Construction Veneer, 2016, Volume 150, p. 1541-1546.

[2] N. R. Galyavetdinov, R. R. Safin, A. E. Voronin, Analysis of physic-mechanical properties of $\tau$,соп̆posites based on polylactide and thermally modified wood fibers, 2016 , Volume 870 , p. 202 206.

[3] T. Qiang, D. Yu, Y. Wang, H. Gao, Polylactide - Based Wood Plastic Composites Modified with linear low Density Polyethylene, 2013, Volume 52, p. 149-156.

[4] T. Qiang, D. Yu, H. Gao, Y. Wang, Polylactide - Based Wood Plastic Composites Toughened with SBS, 2012, Volume 51, p. 193 198.

[5] Y. Li, H. Shimizu, Toughening of polylactide by melt blending with a biodegradable poly(ether)urethane elastomer, 2007, Volume 7, p. 921-928.

[6] W. L. Murfy, D. N. Kohn, D. H. Mooney, Growth of continuous bonelike mineral within porous poly (lactide-co-glycolide) scaffolds in vitro.- J Biomed Mater Res, 2000, v. 50(1), p. 186-94.

[7] C. E. Holy, S. M. Dang, J. E. Davies, M. S. Shoichet , In vitro degradation of a novel poly(lactide-co-glycolide) $75 / 25$ foam.- J. Biomaterials; 1999, v. 20(13), p. 1177-85.

[8] H. Peltoniem, D. Hallikainem, T. Towonen, T. Waris, SR-PLLA and SR-PGA miniscrew.- J. Craniomaxillofac/ Surg, 1999, v. 27(1), p. $42-50$.

[9] J. Pilipovic-Crcic, I. Jalsenjan, Albumin-loaded PLA and PLGA microspheres: in vitro evalution.- J. Boll Chim Foam; 1999, v. 138(1), p. 124-94. 